\title{
Nitrogen-containing aromatic compounds: quantitative analysis using gas chromatography with nitrogen phosphorus detector
}

\author{
Yuan Rao ${ }^{1,2} \cdot$ Arno de Klerk ${ }^{1}$ (D) \\ Received: 22 November 2020 / Accepted: 25 January 2021 / Published online: 6 March 2021 \\ (c) The Author(s) 2021
}

\begin{abstract}
The nitrogen-containing aromatic compounds found in the petrochemical industry are varied and extend beyond classes such as the anilines, pyrroles and pyridines. Quantification of these nitrogen-containing compounds that may occur in complex mixtures has practical application for quality assurance, process development and the evaluation of conversion processes. Selective detection of nitrogen-containing species in complex mixtures is possible by making use of gas chromatography coupled with a nitrogen phosphorous detector (GC-NPD), which is also called a thermionic detector. Despite the linearity of the NPD response to individual nitrogen-containing compounds, the response factor is different for different compounds and even isomers of the same species. Quantitative analysis using an NPD requires species-specific calibration. The reason for the sensitivity of the NPD to structure is related to the ease of forming the cyano-radical that is ionized to the cyanide anion, which is detected. The operation of the NPD was related to the processes of pyrolysis and subsequent ionization. It was possible to offer plausible explanations for differences in response factors for isomers based on pyrolysis chemistry. Due to this relationship, the NPD response can in the same way be used to provide information of practical relevance beyond its analytical value and a few possible applications were outlined.
\end{abstract}

Keywords Thermionic detector $\cdot$ Nitrogen phosphorus detector (NPD) $\cdot$ Cyano-radical $\cdot$ Pyridine pyrolysis

\section{Introduction}

Nitrogen-containing aromatic compounds in the petrochemical and pharmaceutical industries are varied and include compound classes that extend well beyond the anilines, pyridines and pyrroles. In terms of abundance, coal tar historically used to be the primary source of nitrogen-containing compounds and most aromatic chemicals, but this situation changed in the period after the 1950s, with petroleum becoming the main source [1]. Despite a sizable market for these compounds, the market resembles that of specialty petrochemicals [2] and it has considerable product diversity.

The constructive petrochemical use of nitrogen-containing aromatic compounds is unfortunately not the only aspect of these compounds to consider. More often, the

Arno de Klerk

deklerk@ualberta.ca

1 Department of Chemical and Materials Engineering, University of Alberta, 9211-116th Street, Edmonton, AB T6G 1H9, Canada

2 Anton Paar, Canada nitrogen-containing heterocycles are contaminants in feed material to petrochemical processes. Even at low concentration level, of the order $100 \mu \mathrm{g} / \mathrm{g}$, nitrogen compounds can cause noticeable inhibition of hydroprocessing and acid catalysts as is found in processes such as gas oil hydrotreating, hydrocracking, and fluid catalytic cracking [3]. Various strategies for removal of nitrogen-containing compounds have been suggested, but nitrogen-removal is challenging when it is applied to bulk petroleum cuts [4].

When only the total nitrogen or basic nitrogen content of petroleum is of interest, then CHNS analysis or acid titration may be sufficient for analytical quantification. If both the nature and the amount of the nitrogen-containing species matter, then analysis must involve separation and quantification. Gas chromatography is particularly useful for such analyses, but the complexity of petroleum derived materials may make clean chromatographic separation difficult. For such cases gas chromatography in combination with a thermionic detector can be useful.

The thermionic detector, also called a nitrogen phosphorous detector (NPD), is selective towards nitrogen and phosphorous compounds. Nitrogen selective detection of compounds

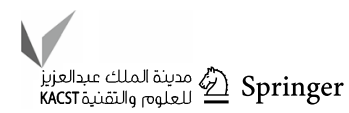


in petroleum is facilitated by the low natural abundance of phosphorus compounds. It was found to be a useful analytical technique for profiling different crude oils [5-7], and to quantify nitrogen-containing compounds in different petroleum cuts [5, 8-10].

The application of an NPD to quantify nitrogen-containing compounds in petroleum and petrochemicals initially appeared to be straightforward. However, a more careful reading of the literature revealed some inconsistencies.

The nature of the NPD response is reportedly mass dependent [11] and the NPD response factor for nitrogen in different compounds was reportedly nearly the same [8]. Yet, Albert [5] stated that the NPD response was only approximately proportional to the nitrogen content and that the response was strictly speaking dependent on the compound structure. This was related to the chemistry taking place in the detector, which requires the formation of a cyano-radial $(\cdot \mathrm{C} \equiv \mathrm{N})$ that is reduced to the cyanide anion $\left(\mathrm{CN}^{-}\right)$and it is the cyanide anion that is detected [12]. Structural features of the molecule that would affect the formation of a cyano-radial, would therefore affect its detection and detector response.

Carlsson et al. [13] provided a more general description of the process. At or close to the hot surface of the NPD, thermal decomposition takes place to produce free radical fragments. Only those free radicals that readily form anions by abstracting electrons from the detector would be detected. Thus, quantification of nitrogen-containing species was not necessarily proportional to the nitrogen-content, or the mass of the nitrogen-containing species, but to depended on how much cyano-radicals were formed in relation to the amount of nitrogen in the species.

The literature on quantification of nitrogen-containing compounds with an NPD is therefore to some extent contradictory.

The justification of this study in the context of petroleum and petrochemicals was twofold. First, to determine how the structure of nitrogen-containing aromatic compounds affected their quantification using gas chromatography with nitrogen phosphorus detector. Quantification of these compounds has practical application for quality assurance, process development and evaluation of conversion processes. Second, to explore whether the response of the nitrogen phosphorus detector to different nitrogen-containing compounds could be used to learn something about the free radical decomposition of such species in petroleum and petrochemical processes that employed thermal conversion.

\section{Experimental}

\section{Materials}

A variety of nitrogen-containing compounds were commercially obtained from Sigma-Aldrich to evaluate the
NPD response (Table 1). HPLC grade (>99\%) toluene and acetone were purchased from Fisher Scientific as solvents for dilution.

\section{Procedure}

Samples were gravimetrically prepared by dissolving a measured quantity of the analyte in a measured quantity of solvent. Toluene was employed as solvent, unless the nitrogen-containing compound was poorly soluble, or insoluble in toluene, in which case acetone was employed.

Two aspects were experimentally investigated:

1. The linearity of the NPD response was determined by analysis of a set of samples with a range of different

Table 1 Nitrogen-containing compounds employed in this study

\begin{tabular}{|c|c|c|c|}
\hline Compound & Formula & $\mathrm{CASRN}^{\mathrm{a}}$ & Purity ${ }^{b}$ \\
\hline 2-Methylpyridine (2-picoline) & $\mathrm{C}_{6} \mathrm{H}_{7} \mathrm{~N}$ & $109-06-8$ & 0.98 \\
\hline 3-Methylpyridine (3-picoline) & $\mathrm{C}_{6} \mathrm{H}_{7} \mathrm{~N}$ & $108-99-6$ & 0.99 \\
\hline 4-Methylpyridine (4-picoline) & $\mathrm{C}_{6} \mathrm{H}_{7} \mathrm{~N}$ & $108-89-4$ & 0.98 \\
\hline 2,3-Dimethylpyridine (2,3-lutidine) & $\mathrm{C}_{7} \mathrm{H}_{9} \mathrm{~N}$ & $583-61-9$ & 0.99 \\
\hline 2,4-Dimethylpyridine (2,4-lutidine) & $\mathrm{C}_{7} \mathrm{H}_{9} \mathrm{~N}$ & $108-47-4$ & 0.99 \\
\hline 2,5-dimethylpyridine (2,5-lutidine) & $\mathrm{C}_{7} \mathrm{H}_{9} \mathrm{~N}$ & $589-93-5$ & 0.95 \\
\hline 2,6-Dimethylpyridine (2,6-lutidine) & $\mathrm{C}_{7} \mathrm{H}_{9} \mathrm{~N}$ & $108-48-5$ & 0.98 \\
\hline 3,4-Dimethylpyridine (3,4-lutidine) & $\mathrm{C}_{7} \mathrm{H}_{9} \mathrm{~N}$ & $583-58-4$ & 0.98 \\
\hline 2-Ethylpyridine & $\mathrm{C}_{7} \mathrm{H}_{9} \mathrm{~N}$ & $100-71-0$ & 0.97 \\
\hline 4-Ethylpyridine & $\mathrm{C}_{7} \mathrm{H}_{9} \mathrm{~N}$ & $536-75-4$ & 0.98 \\
\hline 2,4,6-Trimethylpyridine & $\mathrm{C}_{8} \mathrm{H}_{11} \mathrm{~N}$ & $108-75-8$ & 0.99 \\
\hline $\begin{array}{l}\text { 2,3,5-Trimethylpyridine }(2,3,5 \text {-col- } \\
\text { lidine) }\end{array}$ & $\mathrm{C}_{8} \mathrm{H}_{11} \mathrm{~N}$ & $695-98-7$ & 0.99 \\
\hline $\begin{array}{l}\text { 3-Cyanopyridine (3-pyridinecarboni- } \\
\text { trile) }\end{array}$ & $\mathrm{C}_{6} \mathrm{H}_{4} \mathrm{~N}_{2}$ & $100-54-9$ & 0.98 \\
\hline Quinoline & $\mathrm{C}_{9} \mathrm{H}_{7} \mathrm{~N}$ & $91-22-5$ & 0.98 \\
\hline Isoquinoline & $\mathrm{C}_{9} \mathrm{H}_{7} \mathrm{~N}$ & $119-65-3$ & 0.98 \\
\hline 4-Methylquinoline (lepidine) & $\mathrm{C}_{10} \mathrm{H}_{9} \mathrm{~N}$ & $491-35-0$ & 0.99 \\
\hline 6-Methylquinoline & $\mathrm{C}_{10} \mathrm{H}_{9} \mathrm{~N}$ & $91-62-3$ & 0.98 \\
\hline 8-Methylquinoline & $\mathrm{C}_{10} \mathrm{H}_{9} \mathrm{~N}$ & $611-32-5$ & 0.97 \\
\hline aniline & $\mathrm{C}_{6} \mathrm{H}_{7} \mathrm{~N}$ & $62-53-3$ & 0.995 \\
\hline 2-Methylaniline (o-toluidine) & $\mathrm{C}_{7} \mathrm{H}_{9} \mathrm{~N}$ & $95-53-4$ & 0.99 \\
\hline 3-Methylaniline ( $m$-toluidine) & $\mathrm{C}_{7} \mathrm{H}_{9} \mathrm{~N}$ & $108-44-1$ & 0.99 \\
\hline 2,4-Dimethylaniline (2,4-xylidine) & $\mathrm{C}_{8} \mathrm{H}_{11} \mathrm{~N}$ & $95-68-1$ & 0.99 \\
\hline 2,6-Dimethylaniline & $\mathrm{C}_{8} \mathrm{H}_{11} \mathrm{~N}$ & $87-62-7$ & 0.99 \\
\hline$N, N$-Dimethylaniline & $\mathrm{C}_{8} \mathrm{H}_{11} \mathrm{~N}$ & $121-69-7$ & 0.99 \\
\hline indole & $\mathrm{C}_{8} \mathrm{H}_{7} \mathrm{~N}$ & $120-72-9$ & 0.99 \\
\hline 3-Methylindole & $\mathrm{C}_{9} \mathrm{H}_{9} \mathrm{~N}$ & $83-34-1$ & 0.98 \\
\hline Acridine & $\mathrm{C}_{13} \mathrm{H}_{9} \mathrm{~N}$ & $260-94-6$ & 0.97 \\
\hline Phenanthridine & $\mathrm{C}_{13} \mathrm{H}_{9} \mathrm{~N}$ & $229-87-8$ & 0.98 \\
\hline Pyrazine & $\mathrm{C}_{4} \mathrm{H}_{4} \mathrm{~N}_{2}$ & $290-37-9$ & 0.99 \\
\hline
\end{tabular}

${ }^{\text {a } C A S R N ~ C h e m i c a l ~ A b s t r a c t s ~ S e r v i c e s ~ R e g i s t r y ~ N u m b e r ~}$

${ }^{\mathrm{b}}$ This is the mass fraction purity of the material guaranteed by the supplier; material was not further purified 
concentrations. The analytes selected were pyrazine that contains two nitrogen atoms and quinoline that contains one nitrogen atom. Acetone solutions were prepared that contained both pyrazine and quinoline at equal nitrogen concentration ( $\mu \mathrm{g} \mathrm{N} / \mathrm{g}$ solution). Acetone was used as solvent for this specific analysis because pyrazine is soluble in acetone, but poorly soluble in toluene.

2. The proportionality of the NPD response to nitrogen in different compounds was measured at a fixed concentration of $1600 \mu \mathrm{g} / \mathrm{g}$. For this study the compounds were analyzed individually and each analysis was repeated three times. Toluene was employed as solvent for most of these analytes.

\section{Analytical}

The study was performed with an Agilent 7890A gas chromatograph with nitrogen phosphorus detector. The gas chromatograph was equipped with a low polarity Agilent HP-5 ms (19091S-433) fused silica column, $30 \mathrm{~m}$ in length, $250 \mu \mathrm{m}$ inner diameter, and with $0.25 \mu \mathrm{m}$ film thickness. A split/splitless injector was employed with a split ratio of 1:100. Helium was the carrier gas with flow rate of $1 \mathrm{~mL} /$ min. Since the separation required was only between the analyte and solvent, a fairly short temperature program was employed. The initial oven temperature was $80{ }^{\circ} \mathrm{C}$, which was increased to $170{ }^{\circ} \mathrm{C}$ with a ramp rate of $6{ }^{\circ} \mathrm{C} / \mathrm{min}$ and then increased to $300^{\circ} \mathrm{C}$ with a ramp rate of $15^{\circ} \mathrm{C} / \mathrm{min}$. The column was held at $300^{\circ} \mathrm{C}$ for $5 \mathrm{~min}$.

\section{Results and discussion}

\section{Linearity of the NPD}

The first question that was addressed was to determine whether analysis using an NPD is linear over several orders of magnitude as reported by Poole [11]. For this evaluation pyrazine and quinoline were selected. The measured peak area in relation to the concentration of each compound is shown in Fig. 1.

It can be seen from Fig. 1 that the response for both compounds was linear with respect to concentration. The NPD response for pyrazine passed through the origin, but this was not the case for quinoline. The detection limit for quinoline based on the intercept with the baseline was around $85 \mu \mathrm{g} \mathrm{N} / \mathrm{g}$. There was also a more pronounced deviation from the otherwise near linear response at the lowest concentration tested.

The NPD response area in the chromatograms in picocoulomb $(\mathrm{pC})$, i.e. picoampere $(\mathrm{pA}) \times$ seconds $(\mathrm{s})$, was linear with respect to concentration. For specific petrochemical applications where it is necessary to track the change in

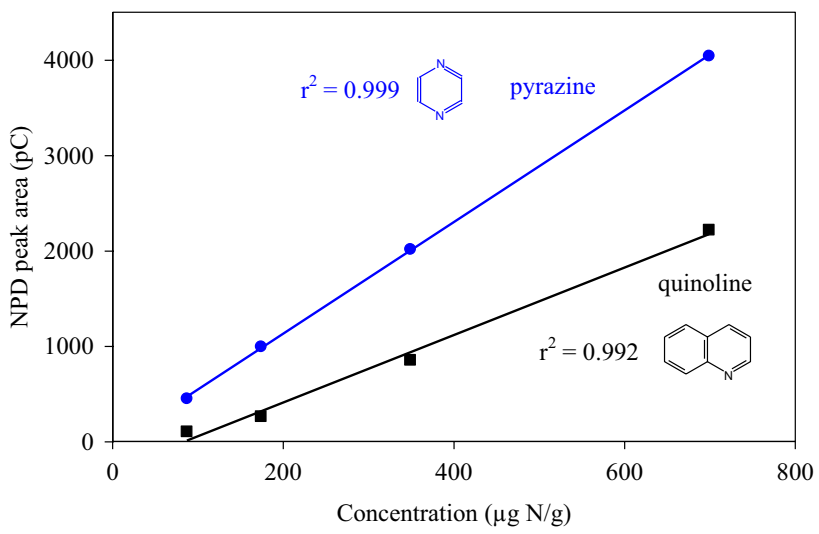

Fig. 1 NPD response with respect to the nitrogen concentration in the form of pyrazine (black circle) and quinoline (black square)

concentration of specific nitrogen-containing compounds, this can be accomplished using calibration for those specific compounds. Once a linear calibration is established, the concentration can be quantified over a few orders of magnitude as indicated by Poole [11].

\section{Proportionality of the NPD}

The second question that was addressed was to determine whether the NPD response was proportional to the amount of the nitrogen-containing compounds as suggested by $\mathrm{Li}$ et al. [8], or approximated the total nitrogen content as suggested by Albert [5]. For this purpose the data in Fig. 1 was employed to calculate the proportionality of the NPD response with respect to nitrogen concentration and the concentration of the nitrogen-containing compound (Table 2).

The relationship between the amount of the two nitrogencontaining compounds and the NPD response was not the same for the two compounds, 2.05 vs. $0.38 \mathrm{pC} /(\mu \mathrm{g} / \mathrm{g})$, for pyrazine and quinoline respectively. The difference in NPD response was so large that it was clear that there was no compound-independent universal relationship between the NPD response the amount of different nitrogen-containing compounds. Comparatively, the difference between the NPD response and the total nitrogen content for the two test compounds was less, $5.85 \mathrm{vs} .3 .54 \mathrm{pC} /(\mu \mathrm{g} \mathrm{N} / \mathrm{g})$, for pyrazine and quinoline respectively. Still, it was clear that there was no compound-independent universal relationship between the NPD response the total amount of nitrogen.

These observations provided indirect support for the claim that the relationship between the NPD response and nitrogen-containing analytes depends on the pyrolysis chemistry and therefore the nature of the species being analyzed. This was investigated further by expanding the number of nitrogen-containing species that were analyzed.

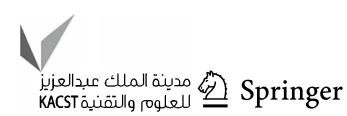


Table 2 NPD response slopes of pyrazine and quinoline

\begin{tabular}{lll}
\hline Description & Pyrazine & Quinoline \\
\hline Linear regression $r^{2}$-value & 0.999 & 0.992 \\
NPD proportionality & & \\
$\quad$ nitrogen mass, $\mathrm{pC} /(\mu \mathrm{g} \mathrm{N} / \mathrm{g})$ & 5.85 & 3.54 \\
nitrogen molar, $\mathrm{pC} /(\mu \mathrm{mol} \mathrm{N} / \mathrm{g})$ & 0.42 & 0.25 \\
nitrogen-compound mass, $\mathrm{pC} /(\mu \mathrm{g} / \mathrm{g})$ & 2.05 & 0.38 \\
nitrogen-compound molar, $\mathrm{pC} /(\mu \mathrm{mol} / \mathrm{g})$ & 164 & 50 \\
\hline
\end{tabular}

${ }^{a}$ The proportionality is expressed as the ratio of the integrated area in the chromatogram of the NPD in picocoulomb (pC) and four different way to express the concentration of the nitrogen-containing compound in the sample solution that was analyzed

\section{NPD response slope for different nitrogen-containing compounds}

Nitrogen-containing compounds (Table 1) were selected to evaluate isomeric diversity of species and to see the influence of differences in compound class. The list of compounds is neither exhaustive, nor is it meant to be representative of the major species found in petroleum or the petrochemical industry. For example, it will be noticed that the pyrroles and carbazoles are under-represented.

The NPD response slopes were determined for individually for solutions of each compound in toluene. Results were ordered according to compound class and are presented in Table 3. The variability in results is expressed in terms of a relative sample standard deviation of the integrated values in picocoulomb for analyses performed in triplicate. The relative sample standard deviation never exceeded $5 \%$.

The pyridine derivatives in Table 3 can be classified into three groups: monomethyl pyridines $\left(\mathrm{C}_{6} \mathrm{H}_{7} \mathrm{~N}\right)$, dimethyl and monoethyl pyridines $\left(\mathrm{C}_{7} \mathrm{H}_{9} \mathrm{~N}\right)$, and trimethyl pyridines $\left(\mathrm{C}_{8} \mathrm{H}_{11} \mathrm{~N}\right)$. The compounds in each group not only have the same molar mass, but also have the same number of moles in the toluene solution. Despite this, the experimental results indicated that the NPD response slopes were different for structurally similar pyridine derivatives. For example, three tested methyl pyridines with methyl substitution on ortho-, meta-, and para-positions have response slopes of 4.85, 6.99, and $6.65 \mathrm{pC} /(\mu \mathrm{g} \mathrm{N} / \mathrm{g})$, respectively. The NPD response was sensitive to the position of substitution, which presumably affected the ease with which cyano-radicals were formed.

The chain length of the alkylated substituent on the pyridines also affected the NPD response, but to a lesser extent than the substituent position. For example, the NPD response slopes of 2-methylpyridine and 2-ethylpyridine were 4.85 and $4.74 \mathrm{pC} /(\mu \mathrm{g} \mathrm{N} / \mathrm{g})$, respectively, and those for 4-methylpyridine and 4-ethylpyridine were 6.65 and 5.74 $\mathrm{pC} /(\mu \mathrm{g} \mathrm{N} / \mathrm{g})$, respectively. The number of alkylated substituents was not a key factor that determined the NPD response
Table 3 NPD response slopes of different nitrogen-containing compounds

\begin{tabular}{|c|c|c|c|}
\hline \multirow[t]{2}{*}{ Compound } & \multicolumn{2}{|c|}{ NPD response ${ }^{a}$} & \multirow{2}{*}{$\begin{array}{l}\text { Uncertainty in } \\
\text { analysis }(\%)^{\mathrm{b}}\end{array}$} \\
\hline & $\mathrm{pC} /(\mu \mathrm{g} \mathrm{N} / \mathrm{g})$ & $\mathrm{pC} /(\mu \mathrm{g} / \mathrm{g})$ & \\
\hline \multicolumn{4}{|l|}{ Pyridines } \\
\hline 2-Methylpyridine & 4.85 & 0.73 & 4.1 \\
\hline 3-Methylpyridine & 6.99 & 1.05 & 3.4 \\
\hline 4-Methylpyridine & 6.65 & 1.00 & 0.6 \\
\hline 2,3-Dimethylpyridine & 6.11 & 0.80 & 0.4 \\
\hline 2,4-Dimethylpyridine & 5.30 & 0.69 & 1.2 \\
\hline 2,5-Dimethylpyridine & 6.27 & 0.82 & 3.7 \\
\hline 2,6-dimethylpyridine & 4.16 & 0.54 & 4.1 \\
\hline 3,4-Dimethylpyridine & 4.41 & 0.58 & 2.3 \\
\hline 2-Ethylpyridine & 4.74 & 0.62 & 3.6 \\
\hline 4-Ethylpyridine & 5.74 & 0.75 & 0.4 \\
\hline 2,4,6-Trimethylpyridine & 5.54 & 0.64 & 0.3 \\
\hline 2,3,5-Trimethylpyridine & 4.93 & 0.57 & 0.7 \\
\hline 3-Cyanopyridine & 7.90 & 1.06 & 1.9 \\
\hline \multicolumn{4}{|l|}{ Quinolines } \\
\hline Quinoline & 3.95 & 0.43 & 4.0 \\
\hline Isoquinoline & 3.77 & 0.41 & 3.1 \\
\hline 4-Methylquinoline & 3.55 & 0.35 & 3.9 \\
\hline 6-Methylquinoline & 2.01 & 0.20 & 4.2 \\
\hline 8-Methylquinoline & 5.59 & 0.55 & 1.6 \\
\hline \multicolumn{4}{|l|}{ Anilines } \\
\hline Aniline & 2.28 & 0.34 & 4.2 \\
\hline 2-Methylaniline & 2.47 & 0.37 & 0.6 \\
\hline 3-Methylaniline & 2.19 & 0.29 & 4.5 \\
\hline 2,4-Dimethylaniline & 2.07 & 0.24 & 4.0 \\
\hline 2,6-Dimethylaniline & 2.62 & 0.30 & 1.4 \\
\hline$N, N$-Dimethylaniline & 5.29 & 0.61 & 2.2 \\
\hline \multicolumn{4}{|l|}{ Indoles } \\
\hline Indole & 2.72 & 0.32 & 4.7 \\
\hline 3-Methylindole & 1.37 & 0.15 & 2.7 \\
\hline \multicolumn{4}{|l|}{ Trinuclear } \\
\hline Acridine & 1.25 & 0.10 & 3.2 \\
\hline Phenanthridine & 1.12 & 0.09 & 3.9 \\
\hline
\end{tabular}

${ }^{\text {a }}$ The proportionality is expressed as the ratio of the integrated area in the chromatogram of the NPD in picocoulomb $(\mathrm{pC})$ and the analyte concentration in either microgram nitrogen per gram of solution $(\mu \mathrm{g}$ $\mathrm{N} / \mathrm{g}$ ), or microgram nitrogen-containing compound per gram of solution $(\mu \mathrm{g} / \mathrm{g})$

${ }^{\mathrm{b}}$ Relative sample standard deviation of NPD response area in picocoulomb (pC) for analyses performed in triplicate

slope. The NPD response did not display any apparent trend for mono-, di-, and trimethylpyridines (Table 3).

As a compound class, the anilines that had amino-groups $\left(-\mathrm{NH}_{2}\right)$ had similar NPD response slopes (Table 3), with values in the range of $2.07-2.62 \mathrm{pC} /(\mu \mathrm{g} \mathrm{N} / \mathrm{g})$, respectively. The only $N$-substituted aniline derivative that was analyzed, was $N, N$-dimethylaniline, and it had a significantly higher 
NPD response, $5.29 \mathrm{pC} /(\mu \mathrm{g} \mathrm{N} / \mathrm{g})$. Having two methyl groups attached to the nitrogen atom might have assisted the formation of cyano-radicals, which could explain the higher NPD response compared to the other anilines.

Quinoline and isoquinoline had near similar NPD response slopes (Table 3), 3.95 and $3.77 \mathrm{pC} /(\mu \mathrm{g} \mathrm{N} / \mathrm{g}$ ), respectively. Considering the 5\% uncertainty, the different in these values were not meaningful. Alkylated derivatives of quinoline displayed the position sensitive variation in NPD response as seen with the alkylated pyridines, with values varying from 2.01 to $5.59 \mathrm{pC} /(\mu \mathrm{g} \mathrm{N} / \mathrm{g})$ depending on the position of the methyl group on the quinoline.

The indoles and trinuclear nitrogen-containing aromatics all had NPD response slopes of around $1-3 \mathrm{pC} /(\mu \mathrm{g} \mathrm{N} / \mathrm{g})$ (Table 3).

In conclusion, the NPD response slopes of different nitrogen-containing compounds in Table 3, were not only affected by compound class, but also by isomeric differences of species. In the case of isomeric species, the observations were consistent with an interpretation that related the NPD response to the pyrolysis chemistry of the compounds. The potential relationship between the pyrolysis chemistry of the nitrogen-containing compounds and the NPD response was worthwhile exploring in more detail.

\section{Selective ion formation in the NPD}

To relate the pyrolysis chemistry of nitrogen-containing compounds to NPD response, it is useful to first look at ionization detectors in more detail.

There are different kinds of ionization detectors that are employed in conjunction with gas chromatography [11]. The most commonly used ionization detector, is the flame ionization detector, which achieves a flame temperature of the order $1500-2000{ }^{\circ} \mathrm{C}$. The flame ionization detector response is roughly related to the amount of carbon in the analyte. For flame ionization detectors the response factor for heteroatom-containing compounds can be estimated using the effective carbon number concept [14-16]. Another modelling approach to relate the analyte structure to detector response was proposed by Katritzky et al. [17], but as with the effective carbon number concept, the number of carbons in the analyte remains a key parameter. The effective carbon number, as opposed to the actual carbon number, takes into account the impact of different functional groups on the efficiency of carbon-based ion formation due to chemical ionization taking place in the hydrogen flame.

The charge carriers in the NPD, which are also responsible for its selectivity, are thermal decomposition products that are produced at much lower temperature than in a flame ionization detector. In the NPD the flow of reaction gases in less and insufficient to maintain combustion as a flame and the temperature achieved is in the range $400-800{ }^{\circ} \mathrm{C}$.
These are pyrolysis conditions and produces radical species. Selectivity is achieved due to ionization on the alkali metal bead in the NPD that acts as an electron donor to free radical species with a high electronegativity, such as those that contain nitrogen and phosphorus as $\cdot \mathrm{CN}, \cdot \mathrm{PO}$, and $\cdot \mathrm{PO}_{2}$ radicals [13]. During the competitive ionization process, more electropositive radicals, such as most hydrocarbon radicals, are not ionized.

The pyrolysis chemistry taking place in the NPD will produce free radical products. However, to detect nitrogencontaining species the pyrolysis chemistry must lead to the formation of the cyano-radical. If the nitrogen is in a more hydrogen rich environment, it is more likely that pyrolysis will lead to ammonia $\left(\mathrm{NH}_{3}\right)$. It should therefore be anticipated that nitrogen-containing compound classes with more hydrogen-rich nitrogen, such as anilines, would on average have a lower NPD response than hydrogen-poor nitrogen, such as pyridines. This is indeed also what was observed (Table 3). The higher NPD response of $N, N$-dimethylaniline with $-\mathrm{N}\left(\mathrm{CH}_{3}\right)_{2}$ compared to anilines with $-\mathrm{NH}_{2}$ can similarly be explained.

\section{Impact of molecular structure of isomers on cyano-radical formation}

What remains to be explained, is the difference in NPD response of structural isomers of the same compound. In an attempt to understand the impact of molecular structure of isomers on NPD response, we looked more closely at the methylpyridines.

Of the three isomers, 3-methylpyridine is the least reactive [18], but under pyrolysis conditions the decomposition reactivity is reversed, with 3-methylpyridine being the most reactive for decomposition at around $800{ }^{\circ} \mathrm{C}$ [19]. From Table 3, the relative NPD responses were in the order: 3-methylpyridine (1) > 4-methylpyridine (0.95) > 2-methylpyridine (0.69). The highest NPD response was the same as the highest pyrolysis reactivity, which was consistent with NPD operation as explained in Sect. 3.4.

The pyrolysis studies of pyridine, 2-methylpyridine and 3-methylpyridine by the group of Mackie [20-24] and the work by Memon et al. [25] provided some insights into the high temperature chemistry relevant to the NPD. The following observations relevant to the present study follow from their work:

a. In all instances hydrogen cyanide was a major product. This is consistent with the cyanide anion being the charge carrier for selective detection of nitrogen-containing compounds by the NPD.

b. Propagation reactions leading to decomposition of 2and 3-methylpyridine formed hydrogen $\left(\mathrm{H}_{2}\right)$, methane $\left(\mathrm{CH}_{4}\right)$, pyridine $\left(\mathrm{C}_{5} \mathrm{H}_{5} \mathrm{~N}\right)$, acetylene $\left(\mathrm{C}_{2} \mathrm{H}_{2}\right)$, hydrogen

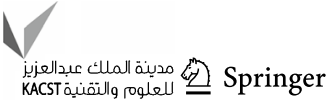


cyanide $(\mathrm{HCN})$, and cyanoacetylene ( $\mathrm{HCCCN})$ as major products [21, 24]. Hydrogen, acetylene, hydrogen cyanide and cyanoacetylene were major products from pyridine pyrolysis [20], and at short context time pyridine pyrolysis produced acetylene, butadiene $\left(\mathrm{C}_{4} \mathrm{H}_{6}\right)$ and methylnitrile $\left(\mathrm{CH}_{3} \mathrm{CH}\right)$ as major initial products [25]. Any differences in the decomposition pathways between these compounds that could give rise to a difference in NPD response must therefore be related to the initial rate and amount of cyanide formation and not due to the overall decomposition reaction network.

c. The likely first step in pyrolysis of the methylpyridine is loss hydrogen from the methyl group attached to the pyridine (Fig. 2). This does not imply that no other initiation steps are possible, such as the dissociation of $\mathrm{C}_{\text {pyridine }}-\mathrm{CH}_{3}$ and $\mathrm{C}_{\text {pyridine }}-\mathrm{H}$ [22], but these are likely minor initiation pathways at the conditions in the NPD. Based hydrocarbons, the bond dissociation energies for benzylic $\mathrm{C}-\mathrm{H}$, aromatic $\mathrm{C}-\mathrm{CH}_{3}$, and aromatic $\mathrm{C}-\mathrm{H}$ are of the order 375,433 , and $472 \mathrm{~kJ} / \mathrm{mol}$ respectively [26]. If initiation by breaking a bond to the heterocycle was the dominant pathway, then the loss of a methyl radical would cause methyl pyridines and pyridine all to proceed by decomposition of a pyridyl radical. This would make it difficult to reconcile the observed difference in NPD response of the different methylpyridine isomers listed in Table 3.

d. If initiation by $\mathrm{C}-\mathrm{H}$ dissociation on the methyl group is indeed the main initiation pathway, then it may be possible to explain the higher NPD response of 3-methylpyridine. As mentioned before, 3-methylpyridine had the highest pyrolysis reactivity of the methylpyridine isomers [19], and this might be due to the resonance structure that is possible after 'benzylic' $\mathrm{C}-\mathrm{H}$ dissociation (Fig. 3). A similar argument as was presented for the formation of the ortho-pyridyl radical to explain initial decomposition that would result in a terminal cyanogroup, which was consistent with the decomposition products formed by pyridine decomposition [20]. The 2-, or 4-methylpyridyl radical does not have the same

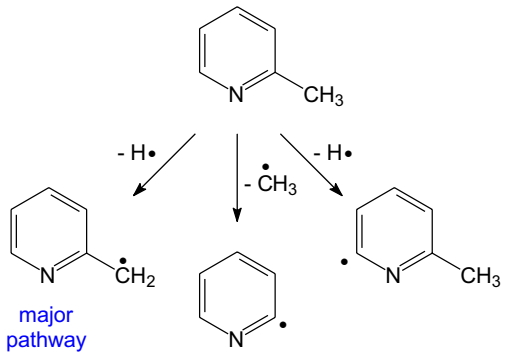

Fig. 2 Initiation of 2-methylpyridine decomposition at NPD conditions convenient resonance structure as shown in Fig. 3, which would explain why decomposition of 3-methylpyridine is easier than the other isomers.

e. There is also a difference in the NPD response between 2- and 4-methylpyridine that should be explained. The pyrolysis of 2-methylpyridine was faster than that of pyridine and loss of the methyl appeared to be an important parallel pathway [23]. It would imply that both 2 - and 4-methylpyridine should resemble pyridine in further decomposition. If there was a difference in decomposition after the loss of the methyl group, to explain the difference in NPD response, it could therefore not be due to pyridyl radical decompositon per se, because the NPD response of 4-methylpyridine > 2-methylpyridine. There had to be a different explanation and possibly one related to the formation of an ortho-pyridyl radical by 2-methylpyridine and a para-pyridyl radical by 4-methylpyridine. One side-reaction that may have bearing on the difference between the isomers, is the formation of heavier products during the pyrolysis of 2-methylpyridine. Ikeda and Mackie [23] analyzed the heavier products and observed that "many of the multiring pyrolysis products have a nitrogen atom adjacent to a benzene ring but not in the $\beta$-position." One of the major primary products from pyridine pyrolysis is butadiene [25], and the addition reaction of butadiene to the ortho-pyridyl radical could be assisted by the adjacent nitrogen (Fig. 4) in a way that is not possible for the para-pyridyl radical. Forming a different stable product as side-reaction from 2-methylpyridine decomposition would not necessarily affect the overall decomposition, but it would reduce the initial decomposition rate to release a cyano-radical to reduce the NPD response of 2-methylpyridine relative to that of 4-methylpyridine.

The present study was not designed to explore the pyrolysis chemistry of the nitrogen-containing compounds. Nevertheless, combining the results in Table 3 with literature observations showed that a relationship between the pathway of initiation leading to initial decomposition and the response of the NPD was able to provide a plausible, but unproven explanation for the difference in NPD response.

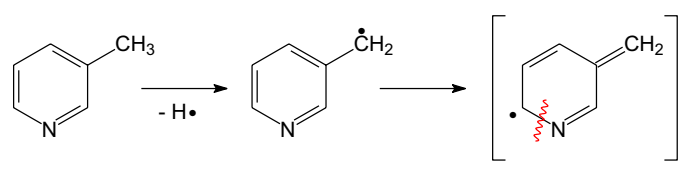

Fig. 3 Possible decomposition sequence responsible for the higher decomposition rate and higher NPD response of 3-methylpyridine 


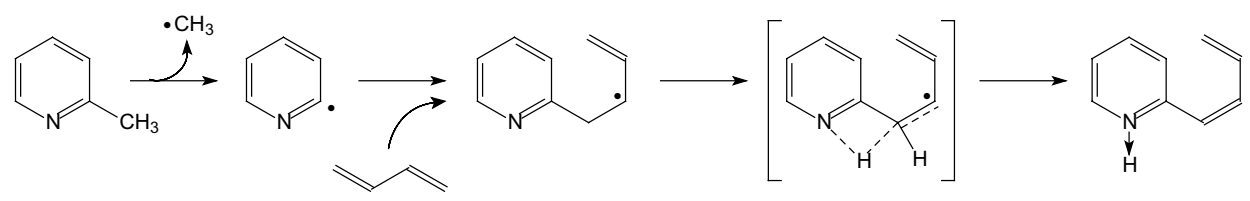

Fig. 4 Side-reaction of the ortho-pyridyl radical formed by 2-methylpyridine decomposition that is assisted by the adjacent nitrogen to reduce initial decomposition rate and decrease the NPD response of 2-methylpyridine

\section{Relevance to petrochemical and other processes}

In the previous section it was shown how NPD response could be related to pyrolysis chemistry of isomeric species. The same type of approach can be used to use the NPD response to assist with elucidating decomposition pathways of interest to petrochemical transformations.

In the same way it could also be an indicator of likely emission products during high temperature processing or destruction of nitrogen-containing materials. The same pyrolytic decomposition that is involved in forming the cyano-radical also leads to the formation of hydrogen cyanide during combustion processes. For example, the nature of the nitrogencontaining species in fuels with the same total nitrogen content affected the HCN yield during combustion [27], which is likely reflected in the NPD response of those materials too.

Analyses using an NPD also have analytical uses beyond those that are self-evident from its selective detection. It may be possible to obtain some indication of the compound class composition of a complex material, such as a petroleum product, by relating the NPD response to the total nitrogen content by CHNS elemental analysis. For example, pyridines on average have a higher NPD response than anilines, which would assist with differentiation between nitrogen bases. Similarly, it may be possible to differentiate between isomers that are difficult to differentiate using mass spectrometry, because isomers of the same species may have different NPD response factors.

These are just some of the potential uses where the NPD response can be related to practical applications through the description of the structure-sensitive reaction chemistry taking place in the NPD.

\section{Conclusions}

The quantification of nitrogen-containing compounds with a nitrogen-phosphorus detector (NPD) was investigated following on contradictory reports on the relationship between the detector response and concentration of nitrogen-containing compounds. It was found that:

a. Despite the linearity of the NPD response to individual nitrogen-containing compounds, the response factor of the NPD is different for different compounds and even structural isomers of the same species. Quantitative analysis using an NPD requires species-specific calibration.

b. The NPD response can be related to the pyrolysis chemistry leading to cyano-radical formation. In the same way the NPD response can be used to provide information of practical relevance beyond its analytical value.

Open Access This article is licensed under a Creative Commons Attribution 4.0 International License, which permits use, sharing, adaptation, distribution and reproduction in any medium or format, as long as you give appropriate credit to the original author(s) and the source, provide a link to the Creative Commons licence, and indicate if changes were made. The images or other third party material in this article are included in the article's Creative Commons licence, unless indicated otherwise in a credit line to the material. If material is not included in the article's Creative Commons licence and your intended use is not permitted by statutory regulation or exceeds the permitted use, you will need to obtain permission directly from the copyright holder. To view a copy of this licence, visit http://creativecommons.org/licenses/by/4.0/.

\section{References}

1. Waddams AL (1973) Chemicals from petroleum, 3rd edn. John Murray, London, pp 209-212

2. Goe GL (1982) Pyridine and pyridine derivatives. Kirk-Othmer encyclopedia of chemical technology, 3rd edn, vol 19. Wiley, New York, pp 454-483

3. Kaiser MJ, De Klerk A, Gary JH, Handwerk GE (2020) Petroleum refining. Technology, economics, and markets, 6th edn. CRC Press, Boca Raton 
4. Prado GHC, Rao Y, De Klerk A (2017) Nitrogen removal from oil: a review. Energy Fuels 31:14-36

5. Albert DK (1978) Determination of nitrogen compound distribution in petroleum by gas chromatography with a thermionic detector. Anal Chem 50:1822-1829

6. Bakel AJ, Philip RP (1990) The distribution and quantitation of organonitrogen compounds in crude oils and rock pyrolysates. Org Geochem 16:353-367

7. Frame GM, Carmody DC, Flanigan GA (1978) An atlas of gas chromatograms of oils using dual flame-ionization and nitrogen phosphorus detectors. Report of the United States Coast Guard Research and Development Center, CGR/DC-3/78, USCG-D-A054966

8. Li N, Ma X, Zha Q, Song C (2010) Analysis and comparison of nitrogen compounds in different liquid hydrocarbon streams derived from petroleum and coal. Energy Fuels 24:5539-5547

9. Machado ME (2019) Comprehensive two-dimensional gas chromatography for the analysis of nitrogen-containing compounds in fossil fuels: a review. Talanta 198:263-276

10. Von Mühlen C, De Oliveira EC, Morrison PD, Zini CA, Caramão EB, Marriott PJ (2007) Qualitative and quantitative study of nitrogen containing compounds in heavy gas oil using comprehensive two-dimensional gas chromatography with nitrogen phosphorus detection. J Sep Sci 30:3223-3232

11. Poole CF (2015) Ionization-based detectors for gas chromatography. J Chromatogr A 1421:137-153

12. Kolb B, Bischoff J (1974) A new design of a thermionic nitrogen and phosphorus detector for GC. J Chromatogr Sci 12:625-629

13. Carlsson H, Robertsson G, Colmsjö A (2001) Response mechanisms of thermionic detectors with enhanced nitrogen selectivity. Anal Chem 73:5698-5703

14. Sternberg JC, Gallaway WS, Jones DTL (1962) The mechanism of response of flame ionization detectors. In: Brenner N, Callen JE, Weiss MD (eds) Gas chromatography. Academic Press, New York, pp 231-267

15. Scanlon JT, Willis DE (1985) Calculation of flame ionization detector relative response factors using the effective carbon number concept. J Chromatogr Sci 23:333-340

16. Jorgensen AD, Picel KC, Stamoudis VC (1990) Prediction of gas chromatography flame ionization detector response factors from molecular structures. Anal Chem 62:683-689
17. Katritzky AR, Ignatchenko ES, Barcock RA, Lobanov VS, Karelson M (1994) Prediction of gas chromatographic retention times and response factors using a general qualitative structure-property relationships treatment. Anal Chem 66:1799-1807

18. Tenenbaum LE (1961) Alkylpyridines and arylpyridines. In: Klingsberg E (ed) Pyridine and its derivatives. Part II. Interscience, New York, pp 155-298

19. Hurd CD, Simon JI (1962) Pyrolytic formation of arenes. III. Pyrolysis of pyridine, picolines and methylpyrazine. J Am Chem Soc 84:4519-4524

20. Mackie JC, Colket MB III, Nelson PF (1990) Shock tube pyrolysis of pyridine. J Phys Chem 94:4099-4106

21. Terentis A, Doughty A, Mackie JC (1992) Kinetics of pyrolysis of a coal model compound, 2-picoline, the nitrogen heteroaromatic analogue of toluene. 1. Product distributions. J Phys Chem 96:10334-10339

22. Doughty A, Mackie JC (1992) Kinetics of pyrolysis of a coal model compound, 2-picoline, the nitrogen heteroaromatic analogue of toluene. 2. The 2-picolyl radical and kinetic modeling. J Phys Chem 96:10339-10348

23. Ikeda E, Mackie JC (1995) Thermal decomposition of two coal model compounds-pyridine and 2-picoline. Kinetics and product distributions. J Anal Appl Pyrolysis 34:47-63

24. Jones J, Bacskay GB, Mackie JC (1996) The pyrolysis of 3-picoline: $a b$ initio quantum chemical and experimental (shock tube) kinetic studies. Isr J Chem 36:239-248

25. Memon HUR, Bartle KD, Taylor JM, Williams A (2000) The shock tube pyrolysis of pyridine. Int J Energy Res 24:1141-1159

26. Blanksby SJ, Ellison GB (2003) Bond dissociation energies of organic molecules. Acc Chem Res 36:255-263

27. Moreea-Taha R (2000) NOx modelling and prediction. IEA Coal Research, London, p 12

Publisher's Note Springer Nature remains neutral with regard to jurisdictional claims in published maps and institutional affiliations. 